\title{
Fibroma de Células Gigantes en Lactante Mayor
}

\author{
Giant Cell Fibroma in Older Infant. A Case Report
}

\begin{abstract}
Francisco Villavicencio Ventura; Jesús Luengo Fereira; Martha Hernández Montoya; Edgar Reyes Méndez; Obed Lemus Rojero \& Heraclio Reyes Rivas
\end{abstract}

VILLAVICENCIO, V. F.; LUENGO, F. J.; HERNÁNDEZ, M. M.; REYES, M. E.; LEMUS, R. O. \& REYES, R. H. Fibroma de células gigantes en lactante mayor. Reporte de un caso. Int. J. Odontostomat., 12(2):93-96, 2018.

RESUMEN: El fibroma de células gigantes es considerado un tumor benigno no neoplásico de la mucosa oral. Este aparece en las primeras tres décadas de la vida, siendo relativamente raro en pacientes pediátricos. Puede encontrarse principalmente en la encía mandibular, mostrando predilección por el sexo femenino. Clínicamente se presenta como un crecimiento indoloro, de base sésil o pediculado, que generalmente se confunde con otras lesiones de tipo fibrosas como los fibromas de irritación. Histológicamente, se distingue por presentar fibroblastos estrellados con la presencia de células gigantes multinucleadas cerca de la lámina del epitelio. Presentamos el caso de una paciente femenino de un año de edad la cual presenta crecimiento nodular indoloro en relación con una superficie del paladar de 51 y 61 . Teniendo en cuenta el tamaño y la ubicación de la lesión, se realizó escisión, biopsia y se envió para análisis histopatológico que confirmó la lesión como fibroma de células gigantes.

PALABRAS CLAVE: fibroma de células gigantes, mucosa oral, paciente pediátrico.

\section{INTRODUCCIÓN}

El fibroma de células gigantes es una de las lesiones más comunes de la cavidad bucal (Jimson \& Jimson, 2013), este fue descrito por primera vez por Weathers y Calliham en 1974 como una nueva entidad de hiperplasia fibrosa de tejido blando (Bagheri et al., 2015). Una de las hipótesis más aceptadas sobre su origen es que se produce como respuesta a un trauma o a la recurrencia de una inflamación crónica (Reddy et al., 2015; Barboza et al., 2016). Aparece con mayor frecuencia dentro de las tres primeras décadas de vida, con alta predilección por el sexo femenino y afecta más a caucásicos (Sonalika et al., 2014). Clínicamente se observa sésil o pediculados, asintomático, con superficie de apariencia papilar y de consistencia firme o suave (Jimson \& Jimson; Reddy et al.; Barboza et al.). Usualmente mide menos de 1 $\mathrm{cm}$, siendo la encía el sitio más frecuente de aparición, especialmente a nivel mandibular, seguido por la lengua y la mucosa bucal (Jimson \& Jimson; Reddy et al.). Histológicamente consiste en tejido fibroso no inflamatorio con numerosas células fusiformes y estrelladas con citoplasma basófilo, estas células gigantes pueden ser multinucleadas y dendríticas (Barboza et al.), los límites celulares aparecen rodeados de fi- bras de colágeno en algunas áreas, ciertas células pueden mostrar gránulos de melanina, ocasionalmente se observa la presencia de un proceso formado de diversos capilares, rara vez se muestra proceso inflamatorio mono y polimorfonuclear (Mello-Moura et al., 2016).

En ocasiones puede ser confundido con otros agrandamientos tisulares tales como pólipo fibroepitelial, granuloma piogénico y fibroma entre otras lesiones, por lo que el estudio histopatológico es de suma importancia para su diagnóstico (Sonalika et al.). El tratamiento de elección es la excisión quirúrgica y su recurrencia es rara. Existen otras alternativas de tratamiento para este tipo de lesiones como la criocirugía, que utiliza nitrógeno líquido, lo que resulta muy útil en casos de pacientes con alto riesgo para cirugía o alérgicos a la anestesia. Otras técnicas utilizadas son, el bisturí convencional, el bisturí eléctrico, laser de Erbio, laser de neodimio y laser de diodo. Otros autores proponen infiltrar la lesión con Penicilina G, afirmando que esta produce esclerosis de la lesión, desprendiéndola y evitando la recidiva (Correa \& Arias Mendieta, 2016). 
El objetivo del presente trabajo es reportar el caso de una lactante mayor con la presencia de un fibroma de células gigantes en la encía maxilar y parte del paladar duro.

\section{REPORTE DE CASO}

Paciente femenino de un año y seis meses de edad que acude en compañía de su madre a la Clínica Integral de Odontopediatria de la Unidad Académica de Odontología de la Universidad Autónoma de Zacatecas, México; referida del centro de salud, por presentar agrandamiento inusual en la encía maxilar a nivel de los dientes 51 y 61 con una evolución aproximada de 8 meses, asintomático. La madre refiere que la niña no presenta antecedentes médicos relevantes.

A la exploración intraoral, se observa aumento de volumen, de base sésil, consistencia blanda, de forma irregular de aproximadamente $10 \mathrm{~mm}$, localizándose a nivel del frenillo maxilar y se continúa hasta la papila incisiva, atravesando el espacio interproximal entre incisivos centrales superiores, propiciando la separación de los mismos (Fig. 1). Radiográficamente, se observa una zona radiolúcida a nivel del hueso alveolar, entre las raíces de los dientes 51 y 61 , bien delimitada con un diámetro entre 5 a $6 \mathrm{~mm}$ aproximadamente (Fig. 2). Se decide realizar como tratamiento escisión quirúrgica de la lesión, la cual midió aproximadamente 9 mm (Fig.3) y se envía para estudio histopatológico.

El estudio histopatológico mostró una lesión conformada de tejido fibro-conectivo denso, haces de

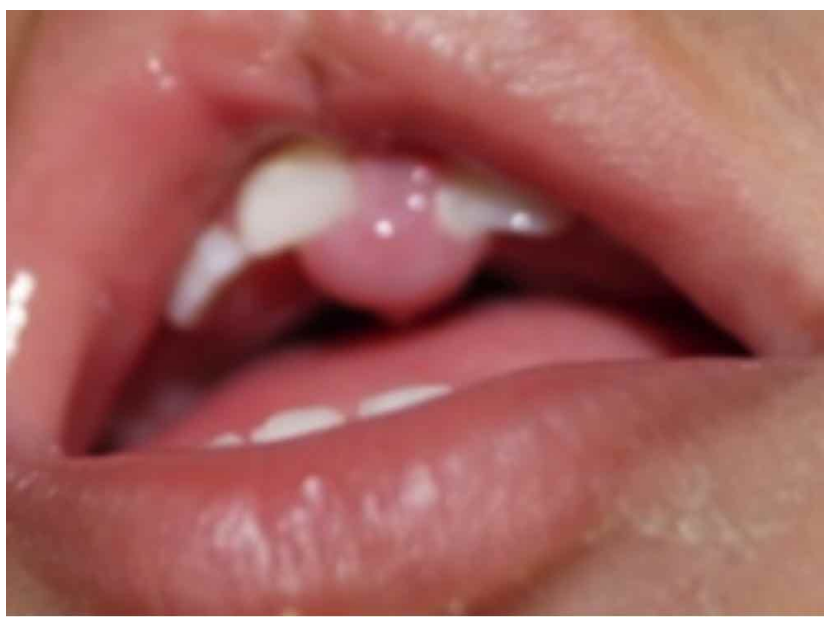

Fig.1. Aspecto clínico de la lesión.

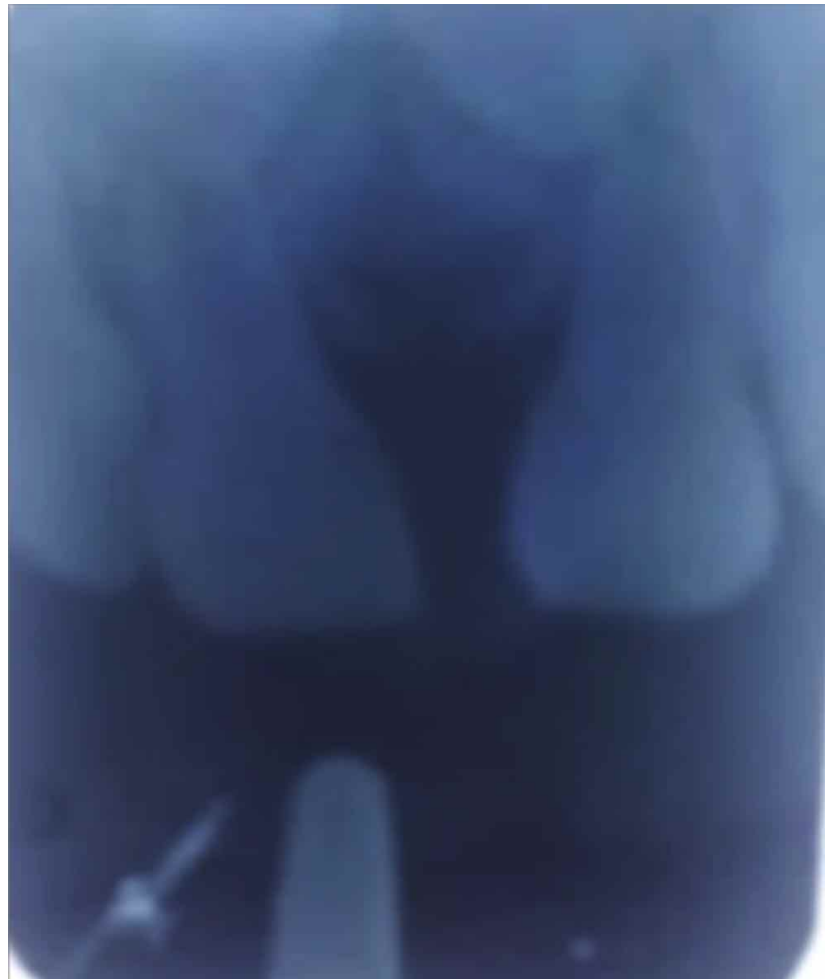

Fig. 2. Radiografía periapical a nivel de la zona de la lesión.

colágeno en disposición irregular, celular (buena cantidad de fibroblastos) bien vascularizados, infiltrado inflamatorio linfoplasmositario leve, el epitelio de cubierta, corresponde a epitelio plano estratificado queratinizado con acantosis y procesos epiteliales elongados, además se muestran adyacentes a la lámina propia del epitelio células de forma estrellada de gran tamaño, lo que lo hace compatible con el diagnóstico de fibroma de células gigantes (Fig. 4).

Se controló al paciente a la semana, al mes y a los 3 meses posterior al tratamiento, donde la mucosa oral y palatina se observa normal y sin recidiva (Fig. 5),

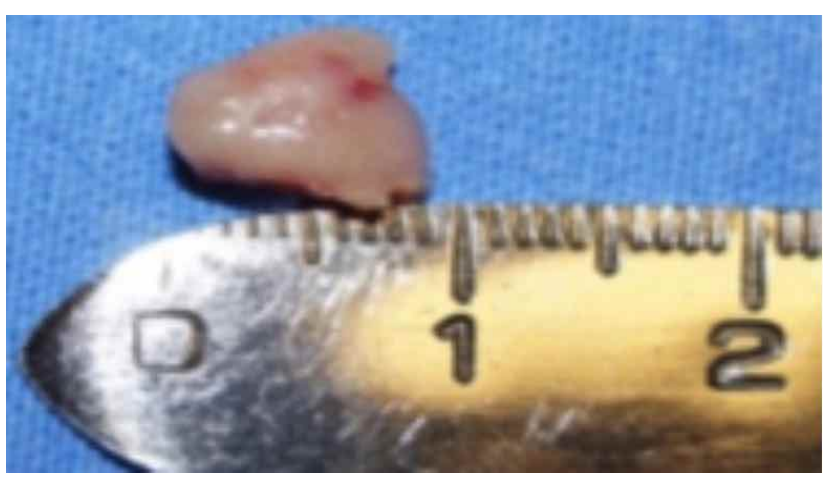

Fig. 3. Diámetro de la lesión. 


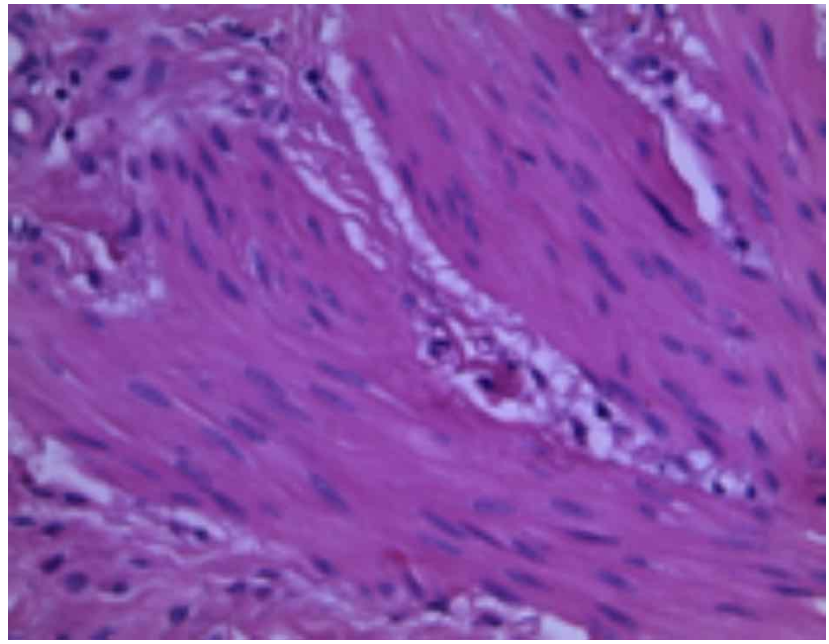

Fig. 4. Tejido fibroconectivo denso (100x).



Fig. 5. Aspecto clínico de la encía a los 3 meses de la cirugía.

\section{DISCUSIÓN}

El fibroma o hiperplasia fibrosa focal, es una de las lesiones que más comúnmente se encuentran en la cavidad oral, se observa frecuentemente en pacientes menores de 30 años con predilección por el sexo femenino (Vergotine, 2012), lo cual es coincidente con el caso presentado, ya que se trató de una paciente femenino de 1 año y 6 meses de edad.

Clínicamente son de base sésil o pediculados, asintomáticos y de consistencia suave o firme, miden aproximadamente $1 \mathrm{~cm}$ (Jimson \& Jimson; Reddy et al.; Barboza et al.), estos datos tienen concordancia con el presente reporte, donde la paciente se encontraba asintomática y a la exploración clínica se observó un aumento de volumen de consistencia suave, base sésil y de aproximadamente $1 \mathrm{~cm}$ de diámetro.
El origen de estas lesiones actualmente no es muy bien comprendido, pero se acepta que aparecen como respuesta ante un trauma, factor irritante o inflamación crónica (Reddy et al.; Barboza et al.). Durante el interrogatorio, no se encontraron datos, hábitos o factores irritantes que pudieran haber influido en su aparición. Este tipo de lesiones es habitual encontrarlas en caucásicos a nivel de encía mandibular (Vergotine; Sonalika et al.), lo cual difiere con lo reportado en este caso, debido a que la paciente es de origen mexicano y la lesión fue encontrada en encía maxilar abarcando el espacio interproximal entre los incisivos centrales superiores hasta la papila incisiva.

El tratamiento de elección es la escisión quirúrgica, inmediatamente después de su remoción debe ser enviada a laboratorio para estudio histopatológico, ya que estas lesiones pueden ser confundidas con otras como el granuloma piogénico o el fibroma periférico. Es importante comentar que las células gigantes multinucleadas o mono nucleadas no son características particulares del fibroma de células gigantes, encontrándose estas características histopatológicas en otras lesiones tales como fibromas ungueales, angiofibroma acral, hiperplasia fibrosa y fibroma de la cavidad oral (Mello-Moura et al.).

Algunos autores recomiendan el seguimiento de estos pacientes y su control periódico por el latente riesgo de recidiva (Reddy et al.; Barboza et al.), sin embargo, luego de tres meses de seguimiento la paciente se encuentra asintomática y sin signos clínicos de presencia de la lesión.

VILLAVICENCIO, V. F.; LUENGO, F. J.; HERNÁNDEZ, M. M.; REYES, M. E.; LEMUS, R. O. \& REYES, R. H. Giant cell fibroma in older infant. Int. J. Odontostomat., 12(2):93-96, 2018.

ABSTRACT: The giant cell fibroma is a benign nonneoplastic fibrous tumor of the oral mucosa. It occurs in the first three decades of life and is relatively rare in pediatric patients. It can be found predominantly in the mandibular gingiva, showing predilection for females. Clinically it presents as a painless, sessile, or pedunculated growth which is usually mistaken for other fibrous lesions like irritation fibroids. Histologically it is distinguished by the presence of stellated fibroblasts along with multinucleated giant cells near the epithelial sheet. We present a case where a one-year-old female patient presented with a painless nodular growth in relation to a palatesurface of 51 and 61. Considering the size and location of the lesion, excision and biopsy were performed and sent for histopathological analysis which confirmed the lesion as giant cell fibroma.

KEY WORDS: giant cell fibroma, oral mucosa, pediatric patient. 


\section{REFERENCIAS BIBLIOGRÁFICAS}

Bagheri, F.; Rahmani, S.; Azimi, S. \& Taheri, J. B. Giant cell fibroma of the buccal mucosa with laser excision: Report of unusual case. Iran. J. Pathol., 10(4):3147, 2015.

Barboza, C. A. G.; Alves, L. B.; Ginani, F. \& De Figueiredo, C. R. L. V. Gingival giant cell fibroma of unusual size. Rev. Cuba. Estomatol., 53(2):62-6, 2016.

Correa, P. E. \& Arias Mendieta, S. Resección de fibroma en mucosa oral. Técnica del estrangulamiento. Rev. CES Odontol., 29(1):82-7, 2016.

Jimson, S. \& Jimson, S. Giant cell fibroma: A case report with immunohistochemical markers. J. Clin. Diagn. Res., 7(12):3079-80, 2013.

Mello-Moura, A. C. V.; Santos, A. M. A.; Bonini, G. A. V. C.; Zardetto, C. G. C.; Moura-Netto, C. \& Wanderley, M. T. Giant cell fibroma in a two-yearold child. Case Rep. Dent., 2016:7058356, 2016.

Reddy, V. K. K.; Kumar, N.; Battepati, P.; Samyuktha, L. \& Nanga, S. P. Giant Cell Fibroma in a Paediatric Patient: A Rare Case Report. Case Rep. Dent., 2015:240374, 2015.

Sonalika, W. G.; Sahu, A.; Deogade, S. C.; Gupta, P.; Naitam, D.; Chansoria, H.; Agarwal, J. \& Katoch, S. Giant Cell Fibroma of Tongue: Understanding the Nature of an Unusual Histopathological Entity. Case Rep. Dent., 2014:864512, 2014.

Vergotine, R. J. A giant cell fibroma and focal fibrous hyperplasia in a young child: A case report. Case Rep Dent., 2012:370242, 2012.
Dirección para correspondencia: Jesús Alberto Luengo Fereira Programa de Especialidad en Odontopediatría Unidad Académica de Odontología Universidad Autónoma de Zacatecas Carretera a la Bufa S/N Colonia Centro Zacatecas, Zac. MÉXICO

Email: jluengo@uaz.edu.mx

Recibido : 10-01-2018

Aceptado: 13-04-2018 